(C) 2016 IEEE. Personal use of this material is permitted. Permission from IEEE must be obtained for all other uses, in any current or future media, including reprinting/republishing this material for advertising or promotional purposes, creating new collective works, for resale or redistribution to servers or lists, or reuse of any copyrighted component of this work in other works. 


\section{Classifying knowledge-sharing barriers by organisational structure in order to find ways to remove these barriers}

\author{
Van Dong Phung ${ }^{*}$, Igor Hawryszkiewycz \\ University of Technology, Sydney, Australia \\ Email: dongpv@gmail.com*, Igor.Hawryszkiewycz@uts.edu.au
}

\author{
Muhammad Hatim Binsawad \\ The King Abdulaziz University, Saudi Arabia \\ Email: m.sawad@hotmail.com
}

\begin{abstract}
Research in knowledge management (KM) has recently revealed that barriers to knowledge sharing (KS) can significantly influence KS and reduce creativity. KS is a critical contributor to creativity and innovation among individuals in organizations. This paper introduces a framework using the Lotus Blossom technique to classify KS barriers. This technique emphasizes the power of brainstorming on the field of interest by the application of a visual representation of ideas. An exploration of steps to classify barriers is discussed. One of the key aims of the framework is to ensure that barriers can be classified in ways that best identify in order to find ways to remove them. A review of a large number of $\mathrm{KM}$ articles in the literature has identified 160 barriers to $\mathrm{KS}$ in a variety of organizations. These were classified into eight themes: Social, Individual, Culture, Technology, Political, Organization, Content, and Routine, procedure and process. The paper, then, discussed the most significant barriers to KS: Psychological ownership, Lack of a motivation, Lack of trust, Lack of incentive and reward systems, Lack of organization culture, Lack of leadership, Lack of technical support, Insufficient technology infrastructure. Implications and future research in this area are also proposed.
\end{abstract}

Keywords-Knowledge management, Knowledge sharing barriers, Knowledge sharing enablers, Lotus Blossom technique.

\section{INTRODUCTION}

The paper describes ways that knowledge-sharing (KS) barriers can be classified by organizational structure in order to find the ways to remove barriers to facilitate $\mathrm{KS}$ in organizations. The paper identifies a large number of $\mathrm{KS}$ barriers resulting from an examination of the research done by numerous authors across various areas and countries over the past few decades. By using Lotus Blossom technique, the research classifies barriers into categories that will help to find ways to remove barriers to sharing knowledge and lead to increased creativity and innovation in organizations. The study will contribute to enhance our understanding of KS barriers and provide a method to classify KS barriers.

Knowledge has been recognized an intellectual capital of organizations. KS is the key to creativity and innovation in any organization in which managers have struggled to increase the $\mathrm{KS}$ among individuals. Overcoming barriers has become a major driver for the potential success in knowledge management $(\mathrm{KM})$ practices $[5,6,16]$. KS can be defined as a social interaction culture. Through it knowledge, skills, and experiences are exchanged among individuals in the whole department or organization [7]. Identifying the critical barriers to KS which impede $\mathrm{KS}$ between people contributes to the critical debate among academics and practitioners.

Our review of the literature to date has also covered approaches to overcome these barriers in many ways. Disterer [2] examined numerous individual and social barriers that prevented individuals from sharing and transfer their knowledge to others. Based on the findings, the author proposed some suggestions to overcome these inhibitors. These suggestions included how organizations need to strive for a mistake-acceptance culture and to build up a general set of patterns and values for an organization to deal with their trust issues. Nonetheless, this is not enough to classify barriers as the barrier itself comprises several aspects. For example, Riege [14] identified that KS barriers fell into three domains; individual, organizational and technological barriers. His extensive list of potential KS barriers was based on the literature review and the opinions of experts from both academia and industry to accomplish successful KS strategies in organizations. Thanks to his study, many authors have applied this result as a theory in which KS barriers can be seen as three domains organization, technology and individual for many purposes. Moreover, in the research on overcoming KS barriers, Filieri [3] categorized the primary barriers into three main macro-dimensions, social, organizational and cultural, and technological barriers, in order to analyze the relationship between them and new product development performance. In a case study search conducted by Zhou and Nunes [20] in healthcare organizations in China, the four main categories of barriers were found included philosophical divergence, interprofessional tensions, a lack of inter-professional common ground, and insufficient inter-professional education and training. All these studies have revealed that KS barriers are varied and can be classified in different ways, although many of them are intertwined [14].

However, there is still a lack of a more comprehensive and structured method in classifying barriers. It is imperative to find a classification that will provide guidelines on ways to remove barriers. To address this gap, this study used the Lotus Blossom technique to classify KS barriers.

\section{MethodOLOGY}

It is obvious that there are a number of KS barriers which are different from one organization to another. In addition, barriers are identified separately, despite the fact that many of them are intertwined [14]. Thus, there has been a need to 
identify and classify comprehensively structured barriers. To address this, we have developed a framework for the structured classification of barriers as illustrated in Fig. 1.

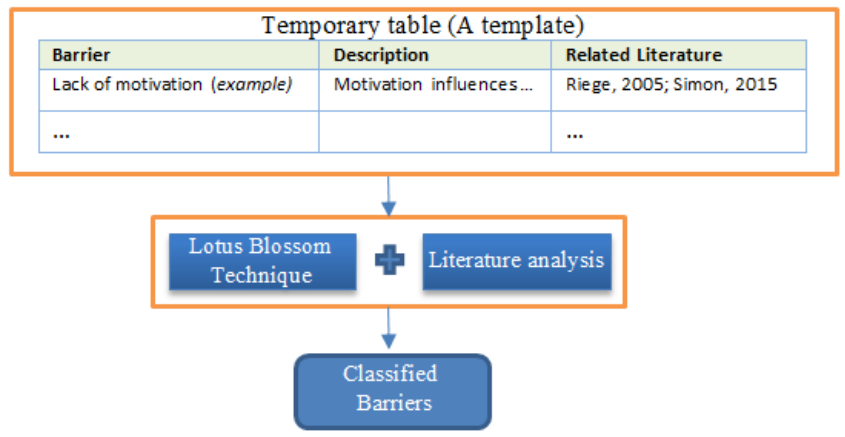

Fig. 1. A framework for structured classification of barriers.

\section{A. Step 1 - Identifying barriers through literature review}

This research conducts a review of a large number of journals. It is based on nomothetic knowledge synthesized by various previous studies [12]. The first step of the framework helps to collect a comprehensive literature of KS barriers. Before being classified, all the barriers found were put in a temporary table as illustrated in Fig. 1. The table includes three columns comprising the name of barriers, a description, and details of the related literature. This table, is not presented here because of word limitations, is to help preliminarily identify the barriers that will be used for brainstorming in Step 2 .

\section{B. Step 2-The Lotus Blossom for classifying barriers}

The Lotus Blossom technique originated from Yasuo Matsumura in Japan. It emphasizes the power of brainstorming on the field of interest through the application of a visual representation of ideas. It is similar to a mind-map, however it is more structured and forces designers in ways differently in classic mind-mapping $[21,22]$.

The process starts with a central theme (KS barriers), and then expands outwards with related barriers (themes) in an iterative manner. The technique facilitates the full fleshing out of an idea prior to considering it complete [22] A single "sheet" is used. The eight $3 \times 3$ box squares are arranged around a center blossom. Fig. 2 illustrates how the overall sheet is presented.

- Box I: The Initial (central) theme. In this case "KS Barriers" that will be classified.

- Boxes A-H: Themes or barriers related to the initial theme in box I (KS Barriers).

- Themes or barriers are all equally considered.

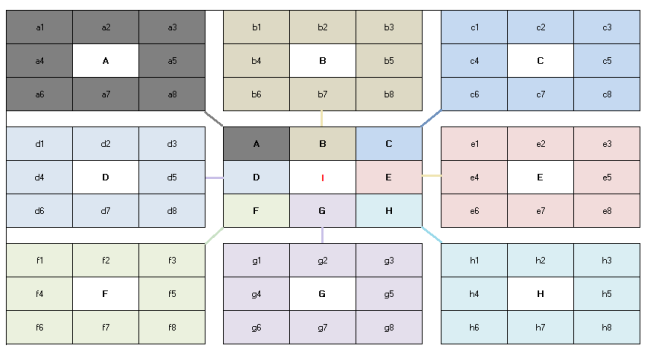

Fig. 2. The overall sheet of Lotus Blossom technique [22].

The steps of the process used here to classify barriers by Lotus Blossom technique in this study are as follows [22]:

1. Firstly: Enter "KS Barriers" as a central theme to be classified in the central box (Box I).

2. Secondly: Brainstorm related themes or barriers based on the literature analysis and put these in the boxes A - H. For example: Social, Individual, Content, etc. The values from boxes $\mathrm{A}-\mathrm{H}$ now are used as the centre of the eight Lotus Blossoms on the outer boxes.

3. Thirdly: Brainstorm related themes or barriers and put these in the eight outer boxes surrounding each of the previous boxes $(\mathrm{A}-\mathrm{H})$ as the new central seed for outer Lotus Blossom to complete all boxes to maximize ideas (themes or barriers). As an example for Box B "Individual", we came up with "Lack of trust" and "Lack of motivation" as barriers of "Individual"; while psychological characteristics is a sub-theme of Individual theme will be expanded.

4. Finally: Brainstorm related themes or barriers to develop lotus blossoms for each sub sub-themes if it is possible. Theoretically, we can identify at least 64 barriers or related themes.

\section{RESULTS}

From the literature review the KS barriers were identified. These barriers, then, were classified as follows.

\section{A. Applying the Lotus Blossom in classifying KS barriers}

We will run through a scenario to classify barriers to find the ways to remove them. Staring with the nine center boxes, we put the "KS Barriers" in the central square as the pistil of a lotus flower then populated the surrounding eight boxes with the barrier-related themes which emerged. By brainstorming, themes related to "KS Barriers" are: Social, Individual, Culture, Technology, Political, Organization, Content, and Routine, procedure and process. The main lotus blossom (level 1) of KS barriers is constructed as shown in Fig. 3.

The values from eight outer boxes in Fig. 3 are now used as the centre of the eight lotus blossoms on the outer boxes.

Based on the literature analysis, each barrier was brainstormed and put in appropriate boxes.

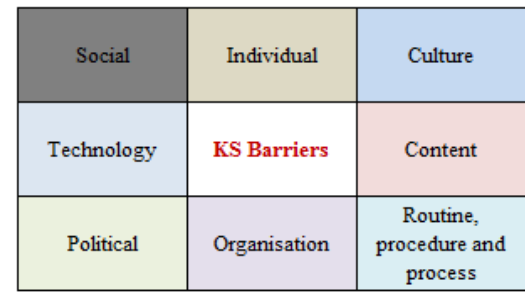

Fig. 3. The main lotus blossom of KS barriers (level 1).

\section{Breaking it down}

We broke down all eight of these boxes into their own outer lotus blossoms (Level 2) and their own sub-outer lotus 
blossoms. However, we will describe only the "Individual" theme and its own sub-themes because of word limitations.

To arrive at the "Individual" breakdown we considered the literature and its implications and came up with the following sub-elements as shown in Fig. 4.

\begin{tabular}{|c|c|c|}
\hline Lack of trust & $\begin{array}{c}\text { Psychological } \\
\text { characteristics }\end{array}$ & $\begin{array}{c}\text { Personal } \\
\text { capacities }\end{array}$ \\
\hline $\begin{array}{c}\text { Age and gender } \\
\text { differences }\end{array}$ & Individual & $\begin{array}{c}\text { Lack of individual } \\
\text { commitment }\end{array}$ \\
\hline $\begin{array}{c}\text { Lack of } \\
\text { motivation }\end{array}$ & $\begin{array}{c}\text { Lack of } \\
\text { awareness }\end{array}$ & $\begin{array}{c}\text { Language } \\
\text { problems }\end{array}$ \\
\hline
\end{tabular}

Fig. 4. The lotus blossom for individual barriers (level 2).

Lack of trust, Lack of motivation, Age and gender differences, Lack of awareness, Language problem, and Lack of individual commitment are individual barriers.

Taking Psychological characteristic and Personal capacities as examples, these become centre themes for the next level of analysis, sub-lotus blossoms (level 3). These are broken down as shown in Fig. 5 and Fig. 6.

\begin{tabular}{|c|c|c|}
\hline $\begin{array}{c}\text { Fear of being } \\
\text { foolish }\end{array}$ & $\begin{array}{c}\text { Fear of losing } \\
\text { face }\end{array}$ & $\begin{array}{c}\text { Lack of } \\
\text { confidence }\end{array}$ \\
\hline Uncertainty & $\begin{array}{c}\text { Psychological } \\
\text { characteristics }\end{array}$ & $\begin{array}{c}\text { Psychological } \\
\text { ownership }\end{array}$ \\
\hline $\begin{array}{c}\text { Knowledge } \\
\text { hoarding }\end{array}$ & $\begin{array}{c}\text { Unwillingness to } \\
\text { leam from others }\end{array}$ & $\begin{array}{c}\text { Different } \\
\text { personalities }\end{array}$ \\
\hline
\end{tabular}

Fig. 5. The sub-lotus blossom for Psychological characteristics (level 3).

\begin{tabular}{|c|c|c|}
\hline $\begin{array}{c}\text { Difference in } \\
\text { education levels }\end{array}$ & $\begin{array}{c}\text { Differences in } \\
\text { experience levels }\end{array}$ & $\begin{array}{c}\text { Lack of } \\
\text { absorptive } \\
\text { capacity }\end{array}$ \\
\hline $\begin{array}{c}\text { Low technical } \\
\text { skills }\end{array}$ & $\begin{array}{c}\text { Personal } \\
\text { capacities }\end{array}$ & $\begin{array}{c}\text { Lack of } \\
\text { experience }\end{array}$ \\
\hline $\begin{array}{c}\text { Poor } \\
\text { communication } \\
\text { skills }\end{array}$ & Personal interact & Personal skills \\
\hline
\end{tabular}

Fig. 6. The sub-lotus blossom for personal capacities (level 3).

\section{Breaking it down for other boxes (level 1) and their own sub-boxes (sub levels)}

By using the same method described above, other barriers were classified in sub-themes as shown in Fig. 7 to Fig. 13.

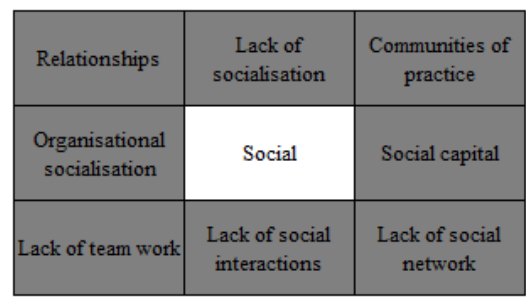

Fig. 7. The lotus blossom for social barriers.

- Social barriers have a theme "Relationships" related to "Social" need to be broken down. The lotus blossom for "Relationships" was constructed, but it is not shown here because of word and space limitations. These relationshiprelated barriers consist of Arduous relationships; Blind favoritism towards external knowledge; Internal resistance; Staff retirement; lack or exiguity of network connections; Socialization homophily; Lack of interprofessional ground.

\begin{tabular}{|c|c|c|}
\hline $\begin{array}{c}\text { Change in } \\
\text { technology }\end{array}$ & $\begin{array}{c}\text { Collaboration } \\
\text { tools \& Co- } \\
\text { working }\end{array}$ & Application \\
\hline $\begin{array}{c}\text { Different } \\
\text { conceptual } \\
\text { systems }\end{array}$ & Technology & Network \\
\hline Framework & IT infrastructure & Security \\
\hline
\end{tabular}

Fig. 8. The lotus blossom for technology barriers.

- Similarly, breaking down "Application", the lotus blossom for "Application" was constructed including Lack of appropriate integration of IT systems; Lack of communication and demonstration of advantages of new systems; Lack of compatibility between diverse IT systems and processes; Mismatch user's requirements; Quality of KM system; Software development methodology; incompatible technology; Usability.

\begin{tabular}{|c|c|c|}
\hline $\begin{array}{c}\text { Lack of } \\
\text { incentives and } \\
\text { rewards systems }\end{array}$ & $\begin{array}{c}\text { Lack of social } \\
\text { network }\end{array}$ & $\begin{array}{c}\text { Lack of priority } \\
\text { of knowledge } \\
\text { retention }\end{array}$ \\
\hline $\begin{array}{c}\text { Status and } \\
\text { reputation }\end{array}$ & Political & $\begin{array}{c}\text { Emphasis on } \\
\text { individual rather } \\
\text { than team }\end{array}$ \\
\hline $\begin{array}{c}\text { External } \\
\text { competitiveness }\end{array}$ & $\begin{array}{c}\text { Knowledge } \\
\text { retention of } \\
\text { highly staff }\end{array}$ & \\
\hline
\end{tabular}

Fig. 9. The lotus blossom for political barriers.

\begin{tabular}{|c|c|c|}
\hline Strategy & Resource & $\begin{array}{c}\text { Organisational } \\
\text { structure } \\
\text { hierarchy }\end{array}$ \\
\hline $\begin{array}{c}\text { Lack of } \\
\text { organisational } \\
\text { infrastructure }\end{array}$ & Organisation & Policy \\
\hline $\begin{array}{c}\text { Top management } \\
\text { support }\end{array}$ & Revelation & $\begin{array}{c}\mathrm{KM} \text { is not well } \\
\text { understood }\end{array}$ \\
\hline
\end{tabular}

Fig. 10. The lotus blossom for organization barriers.

Organization has three sub-themes related to organization are strategy, policy and resource. These were constructed into sub-lotus blossoms, comprising:

- Strategy: Lack of organizational commitment; Lack of top management commitment; Learning orientation and values; Lack of awareness of IT system; Lack of strategic planning; Lack of awareness of the organization strategy and goals; Lack of competitiveness; Lack of sponsorship; Lack of innovation; Integration of KM strategy.

- Resource: Lack of financial resources; High cost; Informal networks; Lack of KS beyond teams and across the organization; Personal movement; KM resources; Physical work environment; Informal networks; Distance.

- Policy: Lack of attention and appreciation; Competitiveness of different units; Strong ties; Staff defection; Emphasis on 
individual rather than team; Knowledge is a private asset; Lack of incentives and rewards systems.

\begin{tabular}{|c|c|l|}
\hline & Procedure & \\
\hline Rountine & $\begin{array}{c}\text { Routine, } \\
\text { procedure and } \\
\text { process }\end{array}$ & Process \\
\hline & Norm & \\
\hline
\end{tabular}

Fig. 11. The lotus blossom for routine, procedure and process barriers.

The lotus blossoms for "Routine, procedure and process" were constructed into four sub-lotus blossoms, involving:

- Routines: Lack of collaboration; Lack of face-to-face communication; inflexibility; Lack of time; Missing integration; Philosophical tension; Professional tension.

- Procedures: Incoherent paradigms; Lack of formalization and dissemination of gathered knowledge; Misaligned measures; Technical support; Top down and bottom up flows; Lack of documentation.

- Processes: Insufficient analysis of past mistakes; Insufficient capture, evaluation, feedback, communication, and tolerance of past mistakes; Lack of integration of KM.

- Norms: Absence of interprofessional training; Discrepancy in terminology; Inadequate interprofessional education; Lack of decision making.

\begin{tabular}{|c|c|c|}
\hline $\begin{array}{c}\text { Accuracy and } \\
\text { credibility of } \\
\text { knowledge }\end{array}$ & $\begin{array}{c}\text { Dispersion and } \\
\text { scarcity of } \\
\text { knowledge }\end{array}$ & $\begin{array}{c}\text { KS entails too } \\
\text { much time \& } \\
\text { effort }\end{array}$ \\
\hline $\begin{array}{c}\text { KS initiation is } \\
\text { intimidating }\end{array}$ & Content & $\begin{array}{c}\text { Dominance in } \\
\text { sharing explicit } \\
\text { over tacit knledge }\end{array}$ \\
\hline $\begin{array}{c}\text { Knowledge } \\
\text { codification and } \\
\text { uniqueness }\end{array}$ & $\begin{array}{c}\text { Hard to manage, } \\
\text { share coordinate, } \\
\text { and articulate }\end{array}$ & $\begin{array}{c}\text { Causal ambiguity } \\
\text { and tacitness of } \\
\text { knowledge }\end{array}$ \\
\hline
\end{tabular}

Fig. 12. The lotus blossom for content barriers.

\begin{tabular}{|c|c|c|}
\hline $\begin{array}{c}\text { Cultural } \\
\text { heterogeneity }\end{array}$ & $\begin{array}{c}\text { Differences in } \\
\text { national culture } \\
\text { or ethnic }\end{array}$ & $\begin{array}{c}\text { Resistance to } \\
\text { change }\end{array}$ \\
\hline $\begin{array}{c}\text { Knowledge- } \\
\text { centered culture }\end{array}$ & Culture & $\begin{array}{c}\text { Organisational } \\
\text { culture }\end{array}$ \\
\hline $\begin{array}{c}\text { Job-related } \\
\text { culture }\end{array}$ & $\begin{array}{c}\text { Risk of losing of } \\
\text { power }\end{array}$ & $\begin{array}{c}\text { Existing corporate } \\
\text { culture does not } \\
\text { provide sufficient }\end{array}$ \\
\hline
\end{tabular}

Fig. 13. The lotus blossom for culture barriers.

Culture has a job-related culture theme embracing: Fear of job security; Risk of losing of power; Fear of not receiving just recognition; Value attributed to experts; Conflict Avoidance; Lack of participation and involvement of employee.

Finally, there has been a full lotus blossom at level 1 and level 2 for comprehensive structured barriers as shown in Fig. 14.

Based on the results of theme analysis by Lotus Blossom technique and literature analysis, the study has found the major barriers to KS that will be discussed in the next section.
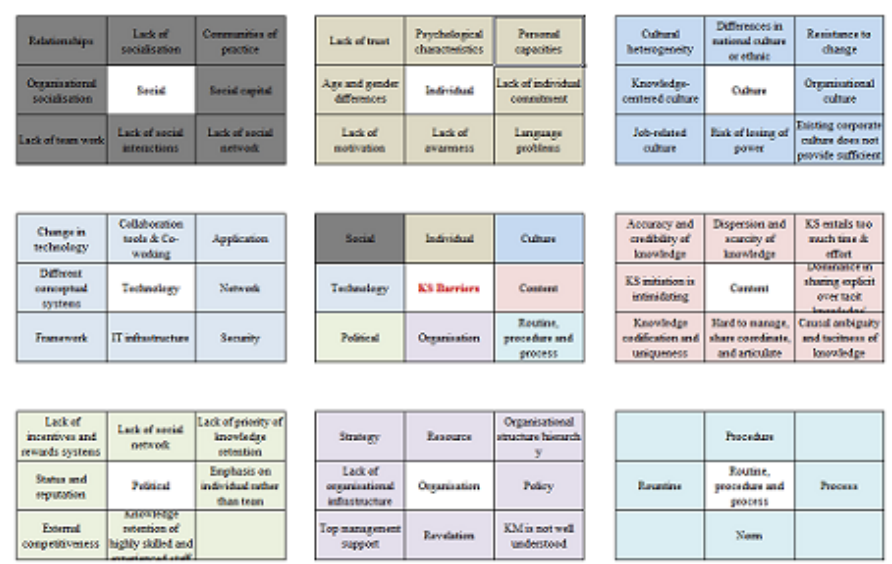

Fig. 14. The holistic lotus blossom for KS barriers (level 1 \& level 2).

\section{B. The major critical barriers}

Riege [14] suggested that barriers which originated from individual behavior or people's perceptions and actions can relate to individuals or groups within or among business functions. Moreover, the main issues of sharing knowledge in an organization is related to the right corporate environment and conditions. He recommended that there are many ways of sharing individual and social or organizational knowledge effectively. Therefore, the research examines some potential organization-based barriers. In addition, technology is able to be as a facilitator to facilitate and support KS processes by making it easier and more effective. However, the primary issue is to select and apply a suitable technology that yields a close fit between people and organizations.

\section{Individual barriers}

- Psychological ownership [1, 2, 4, 12, 14, 13, 18]

Individuals have psychological ownership of knowledge because sharing may decrease or jeopardize personal job security. This will lead to undocumented and could not be used for any productive and effective work in a norganization. Moreover, the saying that "Knowledge is power" is wellknown. People with rare knowledge have the highest reputation and monopolies of knowledge leads to hoarding knowledge instead of sharing it.

- Lack of a motivation $[1,2,4,5,8,12,13,17]$

Motivation influences the KS behaviors of individuals. Some individuals may not anticipate reciprocal profits from sharing their knowledge. Lack of motivation has been recognized as a significant barrier to $\mathrm{KS}$ even when organizations provide all required conditions such as organization commitment, top management support, IT infrastructure, and technical support.

- Lack of trust $[1,3,8,10,12,14,17,18,19]$

$\mathrm{KS}$ is impossible without considering the word trust, as most individuals are unlikely to share their knowledge if they do not trust the person or organization they are to share it with. Thus, several studies on KS indicated that lack of trust among people is the biggest barrier that impedes individuals from sharing knowledge with each other in an organization. 
Individuals may misuse knowledge or take unjust credit for it, leading to lack of trust among them.

\section{Organization barriers}

- Lack of rewards and recognition systems $[1,2,3,9,12,14$, $17,18]$

Although an organization may support KS by providing top management support, a good organizational structure and good IT infrastructure, KS activities could be unsuccessful due to the lack of a transparent rewards and recognition systems.

- Lack of organization culture [1, 10, 11, 12, 14, 18]

"Organizational culture defines the core beliefs, values norms and social customs that govern the way individuals act and behave in an organization" [18]. Individuals socially share their knowledge. Lack of a supportive organizational culture does not deliver adequate support for $\mathrm{KS}$ practices and will eliminate $\mathrm{KS}$ because it is based on organization culture.

- Lack of leadership [2, 8, 12, 14]

Lack of leadership in terms of clearly communicating the benefits and values of KS practices and poor leadership hinder the successful sharing and transfer of knowledge in an organization.

\section{Technology barriers}

- Lack of technical support $[1,8,10,11,14,17,18]$

Lack of technical support is a barrier to knowledge creation, distribution, storage, and application along with organizational learning because a lack of technical support may block communication flows and work routines and procedures.

- Insufficient technology infrastructure [1, 4, 8, 10, 13 17]

Lack of technology infrastructure is a barrier to $\mathrm{KS}$ as it may discourage the successful sharing of knowledge. KS's high cost and the limitation of IT have been proved as a hindrance to $\mathrm{KS}$ in an organization.

\section{Developing enablers for removing barriers}

Many previous studies have been indicated that there are numerous factors influence KS behavior such as enjoyment in helping others, interpersonal trust, leadership, reward and incentive systems, top management support, and information communication technology (ICT) use $[2,7,12,25,26,27,28$, 29]. These factors can also be recognized as enablers to KS in the literature $[7,24]$. They can be used to remove the barriers and will be discussed later.

\section{- Enjoyment in helping others [7]}

Deriving enjoyment from helping others may help individuals to be more favorably oriented toward KS and more willing to share their knowledge. Previous studies revealed that people are basically motivated to contribute knowledge because being engaged in intellectual pursuits and solving problems can be viewed as challenging and enjoyable.

- Interpersonal trust $[2,25,26]$
A precondition for $\mathrm{KS}$ within an organization is an attitude of trust among the organization's team members. Thus, the primary and essential factor for the organization's success is to have trustworthy relationships among individuals that encourage co-workers to become more willing to share knowledge.

- Leadership $[2,12]$

Leadership has been examined as a major KS enabler. It plays a significant role in encouraging $\mathrm{KS}$ in the organization. A leader is not only responsible for developing trust among individuals, but also encouraging them to share their knowledge. Empowering leadership impacts significantly on personal KS behaviors. Several researches revealed that leaders could be a cultural barrier in organizations (unless?) they promote KS behavior.

- Rewards and incentives systems [2, 7, 25, 26]

People believe that they would have a greater positive willingness to both transfer and receive knowledge if they obtain organizational rewards from offering their knowledge. Therefore, the presence of transparent organizational rewards and incentives systems is a contribution to support $\mathrm{KS}$ activities within any organization.

- Top management support [7, 12, 25, 27]

Top management support has been identified as a motivator or important enabler of KS. Top management support positively affects personal willingness to share knowledge with others. There are numerous studies indicating that top management support is vital to building a supportive climate and delivering sufficient resources. Hence, it is imperative for building and providing a positive $\mathrm{KS}$ culture in any organization that there is a perception of top management support for KS intentions.

\section{- ICT use [7, 28, 29]}

ICT has been identified as a major KS enabler because of four main reasons: 1) ICT may be effective in reducing barriers; 2) ICT may enable the access to data storage based information; 3) ICT may be presented with the aim of enhancing processes related to $\mathrm{KS}$; 4) the varied elements relevant to the KS process may be located by ICT. Studies have recently showed that the role of ICT in KS has become more significant with the passage of time because of the advancement in technologies. Various KS mediums related to the use of ICT has identified such as the use of intranet, emails, database, websites, bulletin boards, and electronic forums that effectively facilitate sharing and transfer of knowledge in and outside the organization.

\section{CONCLUSION AND FUTURE WORK}

Undoubtedly, understanding the presence of different KS barriers and finding ways to remove them can help organizations facilitate the creation, transfer and application of knowledge. It contributes to the success of organizations and the knowledge gap in knowledge management in today's global dynamic competitive environment. This paper described ways to classify barriers by organizational structure through a 
framework using the Lotus Blossom technique. The technique was adopted for theme and barrier analysis using the 160 barriers found in the literature review. These were classified in eight themes: Social, Individual, Culture, Technology, Political, Organization, Content, and Routine, procedure and process. The findings also reveal that Psychological ownership, Lack of a motivation, Lack of trust, Lack of incentive and reward systems, Lack of organization culture, Lack of leadership, Lack of technical support, Insufficient technology infrastructure are the top most commonly significant KS barriers. Enablers were also developed to remove the barriers: Enjoyment in helping others, Interpersonal trust, Leadership, Rewards and incentives systems, Top management support, and ICT use.

The list of barriers classified here provides a holistic and structured starting point to all practitioners, researchers and managers in finding ways to remove barriers to facilitate KS. It is essential to KS practices because the first step to success is the identification of barriers in current KS practices [14].

Our goal in the future is to prioritize the barriers which are categorized based on this approach, and then examines which enabler (s) can remove which barrier (s).

The contribution of this study is to provide a method for practitioners, researchers and managers to enhance our understanding of KS barriers and provide a method to classify KS barriers by organizational structure and to contribute to the knowledge gap in KM in general, and KS in particular.

\section{REFERENCES}

[1] A. Anand, R. Kant, and M.D. Singh, "Knowledge sharing in SMEs: Modelling the barriers". Int. J. Manag. Enterp.12, pp. 385-410, Dev. 2013.

[2] G. Disterer, "Individual and Social Barriers to Knowledge Transfer", Conference Proceedings 34th Annual Hawaii International Conference on System Sciences, Los Alamitos, CA:IEEE Press. 2001.

[3] R. Filieri, Overcoming knowledge sharing barriers through communities of practice: empirical evidence from a big automotive supplier. Cambridge Scholars Publishing, Newcastle Upon Tyne.

[4] H. Solli-Sæther, and J. T. Karlsen, "Enablers and barriers of knowledge sharing for offshore outsource ISD project: A case study". International Journal of Information Technology Project Management (IJITPM), vol. 5(2), pp. 44-59, 2014.

[5] D. Hong, E. Suh, and C. Koo, "Developing strategies for overcoming barriers to knowledge sharing based on conversational knowledge management: A case study of a financial company". Expert Systems with Applications, vol. 38, pp.14417-14427, 2011.

[6] J. C. Rivera-Vazquez, L. V. Ortiz-Fournier, and F. R. Flores, "Overcoming cultural barriers for innovation and knowledge sharing", Journal of Knowledge Management, vol. 13(5), pp. 257 - 270, 2009.

[7] H. F. Lin, Knowledge sharing and firm innovation capability: An empirical study. International Journal of Manpower, vol. 28(3/4), pp. 315-332, 2007.

[8] L. Bloice and S. M. Burnett, "Barriers to knowledge sharing in third sector social care: a case study", Journal of Knowledge Management, vol. 20(1), pp. $125-145,2015$.

[9] M. Wendling, M. Oliveira and A. C. G. Maçada, "Knowledge sharing barriers in global teams", Journal of Systems and Information Technology, vol. 15(3), pp. 239-253, 2013.
[10] M. Kukko and N. Helander, "Knowledge Sharing Barriers in Growing Software Companies". Proceedings of the 45th Hawaii International Conference on System Science. pp. 3756-3765, 2012.

[11] M. Kukko, "Knowledge Sharing Barriers in Organic Growth: A Case Study from a Software Company". Journal of High Technology Management Research, vol. 24(1), pp. 18-29, 2013.

[12] Asrar-ul-Haq. Muhammad and A. Sadiar, "A systematic review of knowledge management and knowledge sharing: Trends, issues, and challenges". Cogent Business \& Management, vol. 3(1), 1127744, 2016.

[13] E. M. K. Omar and S. Timothy, "Knowledge Sharing Barriers and Effectiveness at a Higher Education Institution", International Journal of Knowledge Management, v.8(2), pp.43-64, 2012.

[14] A. Riege, "Three-dozen knowledge-sharing barriers managers must consider", Journal of Knowledge Management, vol. 9(3), pp.18 - 35, 2005.

[15] R. Ruggles, The state of the notion. California Management Review, vol. 40(3), pp. 80-89, 1998. doi:10.2307/41165944.

[16] H. Scarbrough, "Knowledge management, HRM and innovation process", International Journal of Manpower, vol. 24(5), pp. 501-16, 2003

[17] B. P. Sharma and M. D. Singh, "Modeling the Metrics of Individual, Organizational and Technological Knowledge Sharing Barriers: An Analytical Network Process Approach." International Journal of Knowledge Management : IJKM; an Official Publication of the Information Resources Management Association 10.1, 2014.

[18] B. P. Sharma and M. D. Singh, "Modeling the Knowledge Sharing Barriers: An ISM Approach", International Journal of Knowledge-Based Organizations, vol .5(1), pp.16-33, 2015.

[19] S. Cleveland and T. J. Ellis, "Rethinking knowledge sharing barriers: A content analysis of 103 studies". International Journal of Knowledge Management, vol. 11 (1), pp. 28-51, 2015.

[20] L. Zhou and M. Nunes, "Identifying knowledge sharing barriers in the collaboration of traditional and western medicine professionals in Chinese hospitals: A case study". Journal of Librarianship and Information Science, 44(4), 238-248, 2012.

[21] Creating Minds, "Lotus Blossom", Internet address: http://creatingminds.org/tools/lotus_blossom.htm

[22] R. Riley, "The Lotus Blossom Creative Technique", Internet address: http://thoughtegg.com/lotus-blossom-creative-technique/

[23] D. Gilmour, How to fix knowledge management. Harvard Business Review, vol. 81(10), pp. 16-17, 2003.

[24] S. Yeşil, T. Büyükbeșe and A. Koska, "Exploring the Link between Knowledge Enablers, Innovation Capability and Innovation Performance.”, International Journal of Innovation Management, vol. 17 (4), 2013.

[25] C. N.-L. Tan and S. M. Noor, "Knowledge management enablers, knowledge sharing and research collaboration: A study of knowledge management at research universities in Malaysia." Asian Journal of Technology Innovation, vol. 21(2), pp. 251-276, 2013.

[26] F. Othman, I. Hawryszkiewycz, and K. Kang, "The Influence of Sociotechnical Factors on Knowledge-based Innovation in Saudi Arabia Firms", The 25th Australasian Conference on Information Systems, Australian Conference on Information Systems, ACIS, Auckland, NewZealand, pp. 1-10, 2014.

[27] H.F. Lin and G.G. Lee, "Perceptions of senior managers toward knowledge-sharing behaviour", Management Decision, vol. 42 (1), pp. 108-25, 2004.

[28] F. Cantoni, M. Bello and C. Frigerio, "Lowering the barriers to knowledge transfer and dissemination: the Italian cooperative banks experience.", In Proceedings of the 9th European conference on information systems, Bled, Slovenia, 2001.

[29] B. Rosen, S. Frust and R. Blackburn, "Overcome barriers to knowledge sharing in virtual teams. Organizational Dynamics", vol. 36(3), pp. 259-273, 2007. 